\title{
Who Are the Good Team Players?
}

\author{
Richard Bannerot \\ Department of Mechanical Engineering \\ University of Houston
}

\begin{abstract}
Working in teams, especially on multidisciplinary projects, is becoming more and more common in engineering as well as in other work environments. However, despite the importance of "team-work" in engineering design, there is little data on the characteristics of "good" and "poor" team players. This paper presents preliminary results from an ongoing, horizontal study of this issue in two engineering design courses, one at the sophomore level and the other at the senior level. Individual demographic, academic, personality (Myers-Briggs type indicators) and personal data, as well as interest and skill level, were gathered for the entire class. The data for those individuals judged to be above average team players and those judged to be below average team players were then compared. Some of the conclusions reached are listed below:

- The women tended to be better team players than the men.

- The better team players tended to be older, with more work and hands-on experience and either Caucasian or Hispanic.

- The better team players tended to have higher college and high school GPAs and higher SAT Verbal scores but lower SAT Analytical scores.

- The better team players tended to have better drawing abilities and, perhaps most important of all, were better self-critics of their own drawing abilities.

As a result of these conclusions several specific recommendation are made which may improve the ability of some students to work more effectively in groups. However, these conclusions and recommendations are based on very limited data, and further study is needed.
\end{abstract}

\section{Introduction}

With all the interest in having our engineering student become good "team players", there is a surprising lack of information in the engineering education literature on how to form good teams, e. g., what are the characteristics of these good "team players." There are several methods and/or criteria used (See Dutson ${ }^{1}$ for a short review.) by which engineering student teams are formed: by similar interests, by mix of personalities, by similarity of personalities, by diversity of skills, by academic diversity (high and low GPAs), by diversity of work experience, by lot, and by student choice. But these selection methods (especially those seeking "diversity" in ability, skills and experience)

Proceedings of the 2003 ASEE Gulf-Southwest Annual Conference

The University of Texas at Arlington

Copyright (C) 2003, American Society for Engineering Education 
seemed to be motivated only by the desire on the part of the instructor to have "equal" or "balanced" teams, not by the desire to create "good" teams. There are a few studies that actually evaluate team performance of "real" groups. Brickell, et al. ${ }^{2}$ looked at the issue of the student's GPA and interest. They formed five sets of groups: Four sets with the commutations of homogenous and heterogeneous GPA and interest and one control set. They concluded that groups with heterogeneous GPA and homogeneous interest performed best. Although this result is intuitively acceptable, the opposite grouping (homogeneous GPA and heterogeneous interest) was second best with essentially the same group rating ( 87.7 to 87.5 with variances of 0.09 and 0.17 , respectively). Hunkeler et al. ${ }^{3}$ provide a more convincing study of the effects of individual characteristics on group performance. They concluded that:1) four person groups outperformed three person groups, and 2) the inclusion of academically outstanding students and students with practical experience increased group performance. They had hoped to draw some conclusions regarding the effect on group performance of the mix of Kolb Learning Styles in the groups, but the distribution of learning styles in the student sample was too skewed. The Myers-Briggs Type Indicators (MBTI) are discussed by McCaulley ${ }^{4}$ as related to success in working in engineering and design teams. She points out the theoretical desirability of having a diverse set of indicators represented on a design team and the fact that $\mathrm{N}$ (intuition) and to a lesser extent I (introversion) and $\mathrm{P}$ (perceptive orientation), which support creativity, would be desirable characteristics for the design team to have. On the other hand, the engineering education literature indicates that "introverts typically outperform extraverts, intuitors outperform sensors, thinkers outperform feelers, and judgers outperform perceivers.",

The author has been teaching the required sophomore design course in the Department of Mechanical Engineering for the past twelve years and has recently become involved in the teaching of the College of Engineering's capstone design course which is taken by the seniors in three departments (Electrical and Computer, Industrial, and Mechanical Engineering). Both courses are project courses in which students work in teams. The students have always ( 22 years for the sophomore course and at least 35 years for the senior course) self-selected to form their own teams. So naturally, there is an incentive to do it differently. Of course, if the teams are to be selected by the instructor, there is the desire to do it effectively. As noted above, the literature provides little help. Thus this project was initiated to determine what is the make-up of effective teams or who are the "good" team players.

\section{Methodology}

The plan was to gather as much data as seemed relevant from each student enrolled in each class in the fall, 2002 semester, to organize the individual student characteristics by the self-formed groups, to conduct a peer evaluation within each group, to evaluation group performance as always at the end of the semester, and then to see what sense could be made of all the data. That plan was followed and some meaningful conclusions made. 
All students in both classes were requested to complete 1) the questionnaire in Fig. 1,2) a Keirsey Temperament $\operatorname{Sorter}^{6}$ (which was used to determine MBTIs), and 3) a peer rating form taken from and explained in Kaufman ${ }^{7}$. (The peer rating scheme was first proposed

$$
\begin{aligned}
& \text { Group number and/or name: } \\
& \text { Individual Identification (if desired) }
\end{aligned}
$$

1 Age (in years)

2 Ethnicity: Hispanic, Caucasian, African-Am, East Asian, Asian, other

3 Sex

$\mathrm{M}$ or $\mathrm{F}$

4 Work experience (effective years)

5 Engineering related work experience (years)

6 Equivalent full time college experience (years or approximate hours completed)

7 High school gpa 14.0

8 College Board Standard Aptitude Test

$$
\text { Verbal }
$$

Analytical (Math)

9 Estimated college gpa 14.0

10 Overall UH gpa

11 Science/engineering related gpa 14.0

12 Non-science/non-engineering gpa 14.0

13 Academic Major

Please respond to the following statements indicating the degree to which you agree or disagree with each.

14 I was looking forward to taking this class

15 I am enjoying (or expect to enjoy) this class

16 I like working in groups

17 I like working in MY group

18 I would change groups if I could

19 I think my group is working effectively

20 Learning to work in groups is important

21 I have experience with hand and power tools

23 I have above average drawing skills

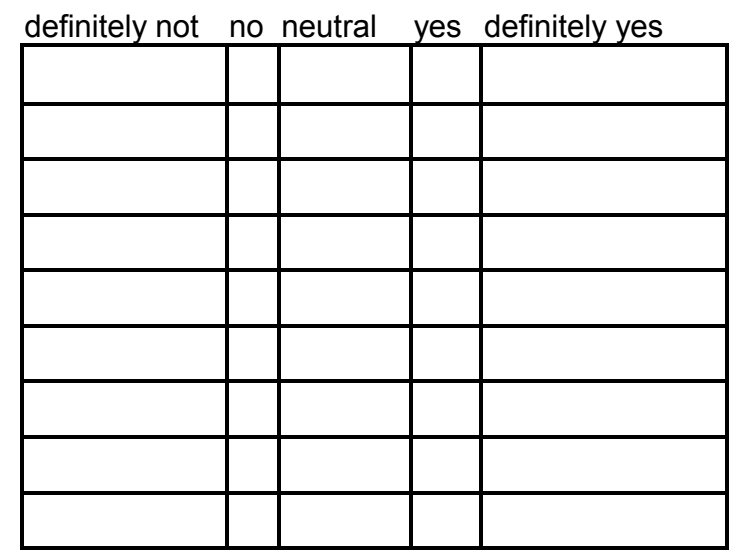

24 Please add any comments regarding your special skills that make you more likely to succeed in this design class:

Figure 1: Demographic Questionnaire

Proceedings of the 2003 ASEE Gulf-Southwest Annual Conference

The University of Texas at Arlington

Copyright (C) 2003, American Society for Engineering Education 
by Brown ${ }^{8}$ and is called the autorating method.) The students were also asked to provide a drawing sample. (Students were instructed to draw a three-dimensional sketch of an object given two views.) Complete records were obtained from 44 of the 50 students initially registered for the senior class which was divided into thirteen self-selected groups, eleven with four members and two with three members. During the semester two students dropped the class resulting in two more groups being reduced to three members. Complete records were obtained from 48 of the 53 students initially enrolled in the sophomore class. Fourteen groups were formed, eleven with four members and three with three members. During the semester all three members of one group dropped. Each course ended up with thirteen groups.

The peer evaluations were used to provide a basis from which to identify the "good" and "poor" team players. The autorating method asks students to rate their group members on a qualitative scale. The rating of each group member is then compared to the group average rating and an individual (quantitative) ranking is determined with some students above and some below average in each group. These results were then examined and modified based on the instructor's knowledge of the groups.

In the sophomore design class half of the semester grade is based on a two month-long "major project". For this project each group had three formal meetings with the instructor during which group members were questioned, several informal meetings with the instructor, some phone conversations with the instructor and numerous email exchanges with the instructor. So even without the peer evaluations, most of the "good" and "poor" group members were already identified. In any event, with some level of subjectivity sixteen "good" team players and twelve "poor" team players were identified.

For the senior course the entire grade is determined from the team's performance on one semester long project. This grade is based on a series of submissions throughout the semester that include individual oral and written assignments for each student. In addition, there are required group meetings with the instructors, questioning during the oral presentations and a final "project defense" in which individuals are asked to state and justify certain design decisions. (See the paper, "Interdisciplinary Capstone Design at the University of Houston" also presented at this conference for details). Through a process similar to that described above for the sophomore class thirteen people were identified as "good" team players, and 6, as "poor". Table 1 summaries the demographic, personality, and personal data from the two classes. Table 2 summarizes the questionnaire data.

\section{Results}

It is first noted that the total population is less than a hundred ( $\mathrm{N}=92$ for the combined classes), so any conclusions are definitely preliminary. There are three sets of data: one set for each class and the combined set. For the most part it makes sense to consider the combined set since the population is larger. However, it some cases it will be useful to consider the data from the individual classes when it appears that an issue might actually be treated differently between seniors and sophomores.

Proceedings of the 2003 ASEE Gulf-Southwest Annual Conference

The University of Texas at Arlington

Copyright (C) 2003, American Society for Engineering Education 


\begin{tabular}{|c|c|c|c|c|c|c|c|c|c|c|c|c|c|c|c|c|c|c|}
\hline & \multicolumn{6}{|c|}{ total population } & \multicolumn{6}{|c|}{ "good" team players } & \multicolumn{6}{|c|}{ "poor" team players } \\
\hline & \multicolumn{2}{|l|}{ soph } & \multicolumn{2}{|c|}{ senior } & \multicolumn{2}{|l|}{ both } & \multicolumn{2}{|l|}{ soph } & \multicolumn{3}{|c|}{ senior } & both & \multirow{2}{*}{\multicolumn{2}{|c|}{ soph }} & \multicolumn{2}{|c|}{ senior } & \multicolumn{2}{|l|}{ both } \\
\hline & \multicolumn{2}{|l|}{$\mathrm{N}=48$} & \multicolumn{2}{|c|}{$\mathrm{N}=44$} & \multicolumn{2}{|c|}{$N=92$} & \multicolumn{2}{|c|}{$\mathrm{N}=16$} & \multicolumn{3}{|c|}{$\mathrm{N}=13$} & $\mathrm{~N}=29$ & & & \multicolumn{2}{|l|}{$\mathrm{N}=6$} & \multicolumn{2}{|l|}{$\mathrm{N}=18$} \\
\hline & $\mathrm{n}$ & $\%$ & $\mathrm{n}$ & $\%$ & $\mathrm{n}$ & $\%$ & $\mathrm{n}$ & $\%$ & & $\mathrm{n}$ & $\%$ & $\mathrm{n}$ & $\mathrm{n}$ & $\%$ & $\mathrm{n}$ & $\%$ & $\mathrm{n}$ & $\%$ \\
\hline \multicolumn{19}{|l|}{ Demographics } \\
\hline Caucasian & 23 & 48 & 11 & 25 & 34 & 37 & 8 & 50 & & 5 & 38 & 1345 & 3 & 25 & 1 & 17 & 4 & 22 \\
\hline Hispanic & 14 & 29 & 11 & 25 & 25 & 27 & 5 & 31 & & 2 & 15 & 724 & 3 & 25 & 1 & 17 & 4 & 22 \\
\hline Asian & 8 & 17 & 15 & 34 & 23 & 25 & 2 & 13 & & 3 & 23 & $\begin{array}{ll}5 & 17\end{array}$ & 4 & 33 & 3 & 50 & 7 & 39 \\
\hline African Am & 1 & 2 & 5 & 11 & 6 & 7 & 0 & 0 & & 1 & 8 & 1 & 0 & 0 & 1 & 17 & 1 & 6 \\
\hline Other & 2 & 4 & 2 & 5 & 4 & 4 & 1 & 6 & 2 & 2 & 15 & 310 & 2 & 17 & 0 & 0 & 2 & 11 \\
\hline Male & 33 & 69 & 33 & 74 & 66 & 72 & 9 & 57 & & 10 & 75 & 1966 & 10 & 83 & 5 & 83 & 15 & 83 \\
\hline Female & 15 & 31 & 11 & 25 & 26 & 28 & 7 & 43 & & 3 & 25 & 1034 & 2 & 17 & 1 & 17 & 3 & 17 \\
\hline Age & 21.6 & & 24.3 & & 22.9 & & 22.5 & & & 25.5 & & 23.8 & 21.1 & & 23.7 & & 21.9 & \\
\hline \multicolumn{19}{|c|}{ Personality: Myers-Briggs; data given in per cent } \\
\hline Extraversion & 57 & & 59 & & 58 & & 53 & & & 57 & & 55 & 59 & & 33 & & 50 & \\
\hline Sensation & 51 & & 64 & & 57 & & 46 & & & 69 & & 56 & 45 & & 83 & & 58 & \\
\hline Thinking & 65 & & 69 & & 67 & & 56 & & & 81 & & 67 & 63 & & 67 & & 64 & \\
\hline Judging & 84 & & 83 & & 84 & & 87 & & & 77 & & 83 & 59 & & 92 & & 70 & \\
\hline \multicolumn{19}{|l|}{ Personal Data } \\
\hline Work (yrs) & 4.40 & & 4.60 & & 4.50 & & 3.90 & & & 4.85 & & 4.33 & 3.40 & & 4.00 & & 3.60 & \\
\hline HS gpa & 3.48 & & 3.39 & & 3.44 & & 3.67 & & & 3.23 & & 3.47 & 3.25 & & 3.14 & & 3.21 & \\
\hline college gpa & 3.04 & & 3.08 & & 3.06 & & 3.38 & & & 3.05 & & 3.23 & 3.04 & & 3.10 & & 3.06 & \\
\hline SAT V/M & $503 / 6$ & & $510 / 6$ & & $506 / 6$ & & $527 / 6$ & & & $526 / 6$ & & $527 / 640$ & $503 / 66$ & & $403 / 7$ & & $465 / 67$ & \\
\hline
\end{tabular}

Table 1: Demographic, Personality, and Personal Data from the Two Classes.

\section{Demographics}

Caucasian students seem to be better team players since they are the only group that appears in the "good" team players category more frequently than their appearance in the class and in the "poor" team player less frequently than their appearance in the class. The Hispanic students appear at almost the same rate in all three categories ("good", "poor" and "class"). Asian students appear in the "poor" team player category at a rate which is more than $50 \%$ above their rate in the class. Taken together the "minority" group (non-Caucasian, non-Hispanic), represent $36 \%$ of the classes, but only $30 \%$ of the "good" team players and $56 \%$ of the "poor" team players.

Females uniformly perform better in the group environment than males. One statistic that stands out is the fact that only three of the 26 females (11\%) were "poor" group members compared to 15 of $66(22 \%)$ of males. 


\begin{tabular}{llllllll}
\multicolumn{2}{c}{ total population } & \multicolumn{2}{c}{ "good" team players } & \multicolumn{2}{c}{ "poor" team players } \\
soph & senior & both & soph & senior both & soph & senior both \\
$N=48$ & $N=44$ & $N=92$ & $N=16$ & $N=13 \quad N=29$ & $N=12$ & $N=6$ & $N=18$
\end{tabular}

\section{Questionnaire Responses:}

$5=$ strongly agree, $4=$ =agree, 3 =neutral, 2=disagree, $1=$ strongly disagree

14 I was looking forward to taking this class:

$\begin{array}{lllllllll}4.36 & 3.64 & 4.02 & 4.25 & 3.69 & \mathbf{4 . 0 0} & 4.09 & 3.50 & \mathbf{3 . 8 9}\end{array}$

15 I am enjoying this class

$\begin{array}{lllllllll}4.23 & 3.64 & 3.95 & 4.25 & 3.92 & 4.10 & 4.00 & 3.00 & \mathbf{3 . 6 7}\end{array}$

16 I like working in groups

$\begin{array}{lllllllll}3.94 & 4.00 & 3.97 & 3.56 & 3.85 & \mathbf{3 . 6 9} & 4.09 & 3.33 & \mathbf{3 . 8 4}\end{array}$

17 I like working in MY group

$\begin{array}{llllllllll}4.13 & 4.28 & \mathbf{4 . 2 0} & 3.81 & 4.31 & \mathbf{4 . 0 3} & 3.73 & 4.17 & \mathbf{3 . 8 8}\end{array}$

18 I would change groups if I could

$\begin{array}{lllllllll}1.86 & 1.91 & \mathbf{1 . 8 8} & 1.63 & 1.85 & \mathbf{1 . 7 3} & 2.45 & 2.17 & \mathbf{2 . 3 6}\end{array}$

19 I think that my group is working effectively

$\begin{array}{lllllllll}3.98 & 3.95 & 3.97 & 3.88 & 4.23 & \mathbf{4 . 0 4} & 3.86 & 3.67 & \mathbf{3 . 8 0}\end{array}$

20 Learning to work in groups is important

$\begin{array}{lllllllll}4.64 & 4.47 & 4.56 & 4.80 & 4.54 & 4.68 & 4.45 & 4.50 & 4.47\end{array}$

21 I have experience working with hand and power tools

$\begin{array}{lllllllll}4.31 & 3.63 & 3.98 & 4.50 & 4.54 & 4.52 & 4.09 & 4.00 & 4.06\end{array}$

22 I have above average drawing skills

$\begin{array}{lllllllll}3.40 & 3.49 & \mathbf{3 . 4 4} & 3.50 & 3.53 & \mathbf{3 . 5 1} & 3.36 & 3.33 & \mathbf{3 . 3 5}\end{array}$

After assessment of a drawing, instructor's opinion on

"This student has above average drawing skills."

$\begin{array}{lllllllll}2.40 & 3.13 & \mathbf{2 . 7 5} & 3.23 & 3.84 & \mathbf{3 . 5 0} & 2.33 & 2.95 & \mathbf{2 . 5 4}\end{array}$

Table 2: Questionnaire Data from the Two Classes

Age was consistently an issue. In both classes the better team players were on average a year older than the class mean, and the poorer team players were about half a year younger than the class mean.

\section{Personality}

The Myers-Briggs Temperament Indicators, in and of themselves, do not appear to be useful predictors of an individual's performance on a team. However, other research, e.g., [4, 5], indicates that the MBTI make-up on an individual team probably does have an effect on the overall team performance. Based on the combined data, it does appear that introversion (opposite of extroversion) and perception (opposite of judging) indicate a slightly higher probability of a "poor" team player. 


\section{Personal Data}

Perhaps as expected, more work experience and higher high school and college grades increase the probability of a person being an effective team member. An interesting (and perhaps unexpected) result is related to the SAT scores. The "good" team players actually had analytical scores slightly below the class as a whole, but their verbal scores were significantly above the class average. When compared with the scores for the "poor" team players, the results could be termed unexpected: the verbal scores for the "poor" team players are considerably below the "good" players (465 to 527) but their analytical scores are significantly higher (671 to 640). The class averages were 506 (verbal) and 650 (analytical).

\section{Questionnaire Results}

This data is perhaps best examined on ones own, but the following comments seem appropriate:

- The sophomores seemed considerably more enthusiastic about their course than the seniors. As expected the better team players seemed to be enjoying the class more than the poorer team players.

- Students seemed to like working in groups and definitely understood the importance of learning to doing so. They also preferred to remain in their assigned groups even when they were not as involved as they should be although the poorer performers seemed to be "blaming" their group, i.e., higher desire to change groups.

- As others ${ }^{3}$ have noted, "hands-on" experiences seemed to improve ones effectiveness in a group.

\section{Drawing and Critique Skills}

The most dramatic finding of this limited study is the potential use of drawing or sketching skills in identifying "good" team players. Further, it is clear that the student's perception of his/her own skills in this area cannot be trusted in some cases and in fact may also be used as an indicator of teaming skills. Note the last two entries in Table 2. The students were asked to assess their own drawing skill ("I have above average drawing skills."). The two classes responded similarly $(3.4 / 5.0,3.5 / 5.0)$ indicating that half "agreed" and half were "neutral". However, the instructor's evaluation of a drawing sample resulted in a weak "disagree" $(2.4 / 5.0)$ and a neutral (3.1/5.0), respectively for the two classes. For both assessments the "good" team players rated higher than the "poor" team players $(3.51 / 5.0$ to $3.35 / 5.0$ for the self assessed score and 3.50/5.0 to 2.54/5.0 for the instructor based score). Which brings us to the final and perhaps most interesting result. The "good" team players were also the most realistic critics of their own work. Note that for the "good" team players their self evaluation of their drawing skills and the instructor's evaluation of their skills were essentially the same (3.51/5.0 to 3.50/5.0) while the "poor" team players had a greatly inflated opinion of the quality of their own work $(3.35 / 5.0$ to $2.54 / 5.0)$. 


\section{Recommendations}

The point of this paper is not simply to single out demographic or skill level groups as being more or less likely to be good or bad team players. It is to recognize that there are differences in "teaming" ability. The first step in teaching is to identify the need or deficiency. We do not limit the admission to our programs based on age, ethnicity, gender, work experience, or academic success (beyond a certain level), so there is little we can do to change our students in these areas. However, based on very limited data, there do seem to be three issues that we could address if we wish to improve the performance of individuals in groups.

First, communication (both written and graphical) skills seem to correlate positively with individual success in groups. Many engineering programs have been dropping drawing requirements. It seems that we should actually be increasing graphical communication requirements, e.g., sketching and drafting. Second, poor critical evaluation skills correlate strongly with poor performance in a group. As noted in this paper these are difficult skills to teach. Students of the arts devote many years to developing these skills. Engineering program devote little or no time to this issue. We could surely improve. Third, engineering students should be encouraged to be less competitive among themselves while working to make themselves and their classmates as successful as possible. The quantitative nature of mathematics, science and engineering classroom testing and the tendency of instructors to grade by the curve tends to give engineering students the wrong message. The successes demonstrated in collaborative learning experiments ${ }^{9}$ have been striking, but this process needs to be extended to include the entire class or the entire program.

\section{Conclusions}

An attempt has been made to identify the desirable characteristics of "good" team players. Some of these results may have been correctly anticipated. For example, older, more academically successful students with hands-on and work experience seemed to be better candidates for "good" team players. On the other hand, the fact that women and the representatives of the "majority cultures" seemed to do better may not be so obvious. The fact that high analytical and low verbal SAT scores seemed to indicate "poor" team players, may simply be a reflection of the fact that a large fraction of them were Asians, who usually do well in mathematics but tend to have (English) language difficulties. Perhaps surprising to some, personality indicators, i.e., MBTI, seemed to have little correlation with individual success in a group. The students very strongly agreed that working in groups is important and almost as strongly seemed to enjoy the opportunity to do so. It was determined that the ability to express oneself through drawing may be a core skill for working successful in a group. Clearly, it is not the drawing skill itself that matters here but perhaps it is the artistic culture at work. People trained in the arts tend to be more group oriented (easily sharing ideas and willing to participate in group critiques) than the average engineering student who tends to be more solitary and competitive. Finally, the ability to objectively assess ones own artistic skills was seen to be perhaps

Proceedings of the 2003 ASEE Gulf-Southwest Annual Conference

The University of Texas at Arlington

Copyright (C) 2003, American Society for Engineering Education 
the strongest indicator of a "good" team player. Perhaps our engineering students would benefit from a little experience in the Art Department.

\section{References}

1. Alan J. Dutson, Robert H. Todd, Spencer Magleby, and Carl Sorensen, "A Review of Literature on Teaching Engineering Design Through Project-Oriented Capstone Courses," Journal of Engineering Education, January 1997, pp. 17-25.

2. James L. Brickell, David B. Porter, Michael R. Reynolds and Richard D. Cosgrove, "Assigning Students to Groups for Engineering Design Projects: A Comparison of Five Methods," Journal of Engineering Education, July, 1994, pp. 259-262.

3. David Hunkeler and Julie E. Sharp, Assigning Functional Groups: The Influence of Group Size, Academic Record, Practical Experience, and Learning Style, Journal of Engineering Education, October, 1997, pp. 321-332.

4. Mary McCaulley, "The MBTI and Individual Pathways in Engineering Design," Journal of Engineering Education, July/August, 1990, pp. 537-542.

5. F. M. Felder, G. N. Felder, and E. J. Dietz, "The Effects of Personality Type on Engineering Student Performance and Attitudes," Journal of Engineering Education, January, 2002, pp. 3-27.

6. David Keirsey and Marilyn Bates, Please Understand Me: Character and Temperament Types, Prometethesus Nemesis Book Company, Del Mar, CA 92014, 1984, p. 11.

7. Deborah B. Kaufman, Richard M. Felder and Hugh Fuller, "Accounting for Individual Effort in Cooperative Learning Teams" Journal of Engineering Education, April, 2000, pp. 133-140.

8. R. W. Brown, "Autorating: Getting Individual Marks from Team Marks and Enhancing Teamwork," 1995 Frontiers in Education Conference Proceedings, Atlanta, GA, November 2-4, 1995, available at $<$ http://fie.engrng.pitt.edu/fie95/3c2/3c24/3c24.htm>

9. see Richard Felder's website for many examples:

http://www.ncsu.edu/felder-public/Papers/Education_Papers.html\#CL

RICHARD BANNEROT

Richard Bannerot is a Professor of Mechanical Engineering at the University of Houston. His research interests are in the thermal sciences and in engineering design education. For the past twelve years he has taught the required "Introduction to Design" course at the sophomore level and has recently become

Proceedings of the 2003 ASEE Gulf-Southwest Annual Conference

The University of Texas at Arlington

Copyright (C) 2003, American Society for Engineering Education 
involved in the teaching of the college's capstone design course. He is a registered engineer in the state of Texas.

Proceedings of the 2003 ASEE Gulf-Southwest Annual Conference The University of Texas at Arlington

Copyright @ 2003, American Society for Engineering Education 